\title{
PSYCHOSOCIAL RISKS GENERATED BY ASSETS SPECIFIC DESIGN SOFTWARE
}

\author{
Remus Furtună \\ Teritorial Labour Inspectorate Sibiu, remus.furtuna@itmsibiu.ro \\ Angela Domnariu \\ Teritorial Labour Inspectorate Sibiu, angela.domnariu@itmsibiu.ro \\ Petru Lazăr \\ SC Klein Consulting SRL, lazarpetricasb@yahoo.com
}

\begin{abstract}
The human activity concerning an occupation is resultant from the interaction between the psycho-biological, socio-cultural and organizational-occupational factors. Tehnological development, automation and computerization that are to be found in all the branches of activity, the level of speed in which things develop, as well as reaching their complexity, require less and less physical aptitudes and more cognitive qualifications. The person included in the work process is bound in most of the cases to come in line with the organizationaloccupational situations that are specific to the demands of the job. The role of the programmer is essencial in the process of execution of ordered softwares, thus the truly brilliant ideas can only come from well-rested minds, concentrated on their tasks. The actual requirements of the jobs, besides the high number of benefits and opportunities, also create a series of psycho-social risks, which can increase the level of stress during work activity, especially for those who work under pressure.
\end{abstract}

Key words: occupational stress, design, psycho-social risks

\section{Introduction}

The technology, automation and computerization form all sectors of activity increasingly require less physical skills and increasingly more cognitive competences (processing a higher volume of information, which are becoming ever more complex, need to take decisions, assuming several uncertainties etc) organizational competences (time management, the management of resources, etc.) and relational competences (teamwork, assuming greater responsibilities, working with clients, etc) which are potential sources of psychosocial risks.

Workers and their efficiency is influenced by observing the job description, the difficulty level of the performed tasks, monotony, automatization and patterns, precision, the responsibility implied by the activity, skills development, initiative, training, the social prestige of the work task within the company.

\section{Description of the achieving software activity}

The activities for achieving custom software (customer-oriented software), writing activities (programming), modification, testing and support on software products, the planning of the structure and content of the computer's code which is necessary to create and implement software systems, the adaptation of the suited software according to specific requirements of the client computer system, are just some of the activities of programmers and computer specialists.

Human activity related to a profession is emerging from the interaction of psychological biological, socio-cultural and occupational factors. As an essential means of human existence, which takes place based on specific criteria of duration and method of organization, it generates most stressful situations. [1;2;].

When it is carried out an activity in which the risk and overload, the izolation or harm are current, we are dealing with an imbalance, that generates professional situations seen as "stressful".[1;2;3].

EU, EC and National Policy in OSH Sector must be adapted to all changes, new requirements and professional risks in order to promote a good working environment ( physical,mental and social), which mustn't be measured only by the lack of work accidents and occupational diseases, but must ensure physical, mental and psychosocial comfort.[1;2;3;4]. 


\section{Research Paper: Multidimensional diagnosis of occupational stress and psychosocial risks in case of programmers}

\subsection{Objective and premises of the research}

In preparing the present work I started from the ideas that the way we interpret the events around us reflects the degree to which we feel that we can or can not influence the statements.

This study aims to highlight the risk factors and the essential dimensions of the occupational stress, which exists in the IT sector, of the adaptive perceptions used by the participants investigated in the process for achieving job satisfaction and their implications on the work and their state of good behavior.

The premises from which we started this research are:

1. How the workers (programmers) perceive that they can influence the situations in which they are involved, and how they consider that the appraisal of the profesional performance reflect how they work and how much they work, is associated with a higher " level of well being" felt by programmer;

2. When workers enjoy the freedom to lead / organize their own work, their appraisal regarding the way to influence the situations is positive.

\subsection{Study participants, measuring instrument and working procedure}

The design of this research paper is based on multidimensional diagnostic study realized on a group of 22 employees of a company specialized in activities to achieve custom software (software oriented to client, CAEN Code : 6201).

We made a preinvestigation questionnaire based on semi-open questions, in order to identify potential real stressors in IT environment; there have been some discussions with subjects and it was applied the Socio- Pressure Management Indicator [2].

The questionnaires were applied individually. There were requested the voluntary participation and the consent of programmers.

\subsection{Preliminary results}

Because the large volume of information and the complexity of the results, we present and analyze in this work just some significant information regarding the psychosocial risks and the dimensions of occupational stress, generated by the specific "design software" activities.

We have done this study in a company created in 1994. The enterprise policy in the area recruitment is focused predominantly on the recruitment of the students in the last year of university/faculty - the future employees after the graduation.

\section{Stress sources at the work place}

Stress factors most strongly felt:

\subsection{Workload -,, I have too much to do in too short time " \\ Figure 1: Workload}

7

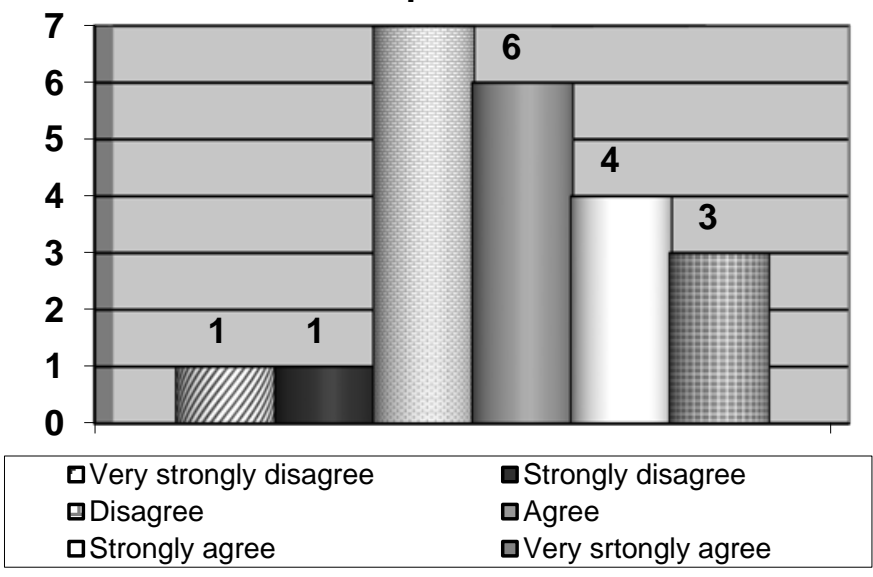


4.2. Distant attitude of teammates materialized in the lack of the support/assistance:

Figure 2: Attitude of teammates

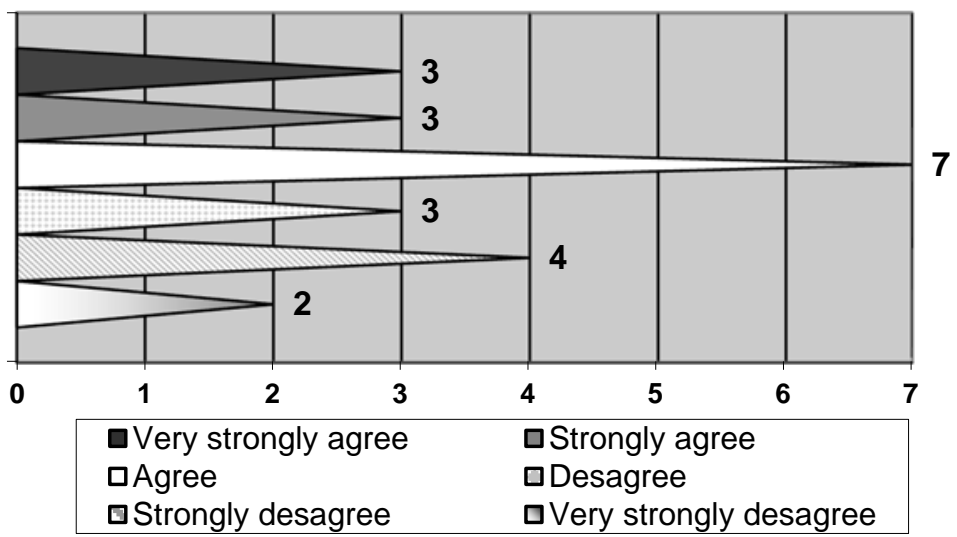

4.3. Unrealistic deadlines for a task:

Figure 3: Deadlines

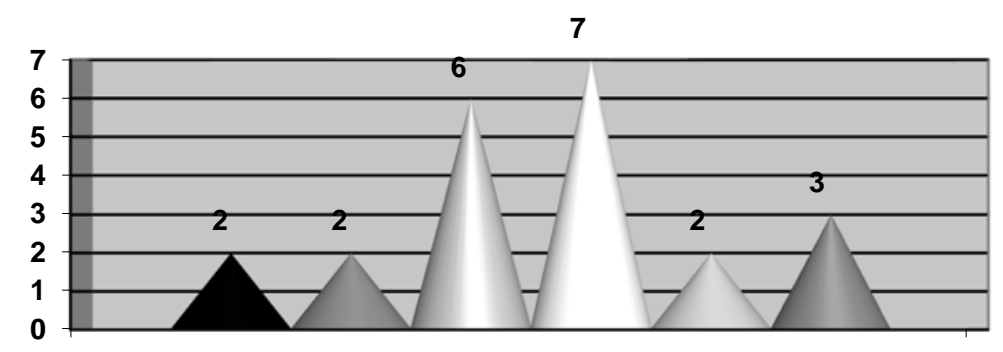

\begin{tabular}{lll}
\hline Very strongly agree & $\square$ Strongly desagree & 口Desagree \\
$\square$ Agree & $\square$ Strongly agree & वVery strongly agree
\end{tabular}

4.4. Carrying out the tasks on time - for example,, i get mad when I'm not able to finish things on time "

Figure 4: Carrying out the tasks on time

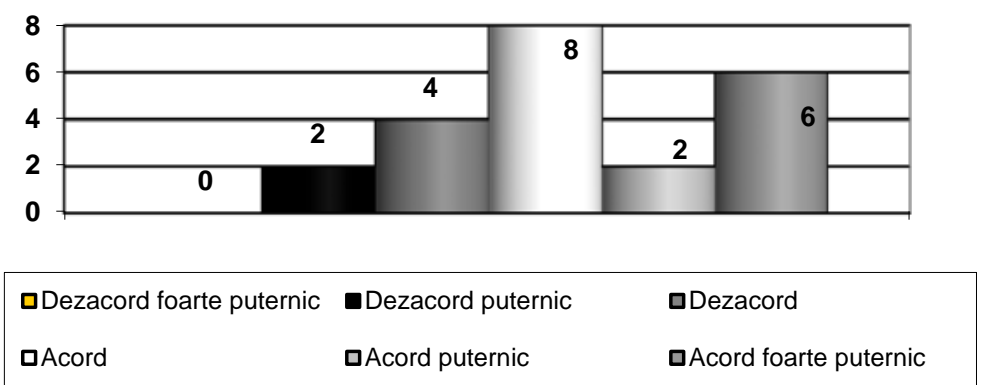

\subsection{The lack of relevant information on what should be done}

A total of 17 developers $(77,27 \%)$ say that manifest agreement, strongly agree and very strong agree and that this is an important factor in carrying out the tasks on time.

In software design activity are present and manifest more or less latent and following psychosocial risks that require a thorough analysis, because:

- Reorganization causes pressure on the personnel $-82 \%$

- The lack of stability in the organization affects the activity of programmers - 78\%

- The degree of involvement in the organization they work for affect behavior at work - $76 \%$

- Level of influence on what happens in the workplace - 65\%

- The way their work is appreciated - $49 \%$

- The availability of colleagues to assist / support the duties - $49 \%$

- The way the organization stimulates the skills development - $45 \%$ 
- Mobilization of energy resources when the pressure starts to increase at the workplace influence their efficiency - $40 \%$

- The existence of some positive mental provisions that helps to overcome difficulties - 39\%

- Freedom of decision in planning and performing work tasks - 33\%.

It is particularly important to underline and appreciate the fact thatthe analized enterprise are the following features:

- $\quad$ None of the current employees no worries about the future of their workplace;

- $\quad 75 \%$ of employees say they have a high degree of control over work they perform;

- $64 \%$,, expressed strong agreement "with the statement,, my work gives me much more pleasure than before",, and 18\% strongly agree ";

- $\quad$ Praises to the workers are more common than reproaches, 88\%;

- Discussions among colleagues about changing jobs are almost nonexistent;

- Although the managers are technically qualified, they don’t compete with his own people and don't impose how to solve a problem, because in this way people can no longer "grow;

- Number of employees who perceive that it is no necessary to respect the time-limits for projects and aren't bothered by this situation represents a $9 \%$.

To increase performance at individual and organizational level we propose the following measures:

a. Identify, eliminate or reduce situational, behavioral and / or attitudes factors that sometimes have a role in not respecting the time-limits for projects finalization;

b. The determination of each programmer to identify their professional aspectsin which he is less efficient and ensuring, by company management, some offers regarding professional training for these areas;

c. After distribution of work tasks specific for software design, the team members should benefit an appropriate time to determine how to solve problems, priorities and a working schedule;

d. Develop a, internal catalog "of software products developed within the company, covering the specific program, its usefulness and the development team, in order to facilitate the access to positive experiences of others, to clarify ambiguities and disturbance during developing a worktask;

e. Presenting an attractive graphical form of the software projects and the progress of the programms.

\section{References}

- Brate, A.T.,Organizational models of occupational stress , E. Avram, Organizational health psychology, Ed. University, Vol. 1, p. 51-73, ISBN 978-973-749-949-3, Sibiu, Romania,(2011).

- Brate, A.T., Towards a comprehensive model-integrative diagnosis and management of organizational stress, E. Avram \& C.L. Cooper, Organizational-managerial psychology. Current Trends, Ed. Polirom, p. 578-591,Sibiu, Romania (2008)

- Brate, A, Multidimensional diagnosis of occupational stress to managers. Human Resources Psychology, Vol. II, Nr. 2, 42-52, Sibiu, Romania (2004).

- Ozcelik, H. \& Barsade, S. Work Loneliness And Employee Performance, Academy of Management Annual Meeting Proceedings (AMBPP): 01 August 2011, 1-6.Pfeifer, J., Veiga, J. (1999). Putting people first for organization success. Academy of Management Executive, 13(2), 37-51. 